\title{
A FICÇÃO E A CONSTRUÇÃO NARRATIVA EM AUTRAN DOURADO: ALGUMAS CONSIDERAÇÕES
}

\section{FICTION AND NARRATIVE CONSTRUCTION IN AUTRAN DOURADO: SOME CONSIDERATIONS}

\author{
Nathaly de Oliveira Rufino ${ }^{1}$ \\ Rodrigo de Albuquerque Marques ${ }^{2}$
}

\begin{abstract}
RESUMO: Tendo em vista que o texto literário é carregado de linguagens e simbologias representativas de um determinado tempo histórico, e suas personagens trazem posturas acionadas sócio culturalmente dentro deste mesmo tempo por eles vivido, objetivamos neste artigo compreender o encontro entre a ficção e as histórias na prosa de Autran Dourado, sobretudo se levarmos em conta que as relações entre estes dois aspectos, em muitos casos, se entrecruzam nas teias das narrativas autranianas.
\end{abstract}

Palavras-chave: Autran Dourado; Ficção; História.

ABSTRACT: Considering that the literary text is loaded with languages and symbologies representing a certain historical time, and its characters bring socio-culturally driven postures within the same time lived by them, we aim in this article to understand the encounter between the fiction and the stories in the prose of Autran Dourado, especially if we take into account that the relations between these two aspects, in many cases, intersect in the webs of the autranian narratives.

Keywords: Autran Dourado; Fiction; History.

\section{INTRODUÇÃO}

Autran Dourado nasceu em Patos, Minas Gerais, em 1926 e faleceu no Rio de Janeiro em 2012. Aos dezessete anos já havia produzido um livro de contos. Acompanhamos uma obra literária planejada em que toma como um dos recursos para a sua construção a paráfrase de si mesmo. Suas obras tratam do íntimo psicológico das personagens, onde a temática da reclusão e da não adequação se repete. No entanto,

\footnotetext{
${ }^{1}$ Mestranda no curso Interdisciplinar de História e Letras pela Universidade Estadual do Ceará com a pesquisa intitulada Duas Pontes: o encontro entre a ficção e a história nas mulheres mineiras de Autran Dourado. E-mail: nathaly.oliveira@aluno.uece.br

${ }^{2}$ Doutor em Literatura Comparada e mestre em Letras pela Universidade Federal do Ceará. Professor Adjunto da Universidade Estadual do Ceará. E-mail: rodrigo.marques@uece.br
} 
através de seu minucioso trato com as palavras, Dourado consegue trazer, em cada livro, um desdobramento peculiar. Nas palavras do próprio autor: "na verdade, estou querendo fazer um livro só [...] meus livros são mais ou menos os mesmos. [...] estou querendo fazer um só personagem" (COSTA, 1974, p. 19).

De início já citamos a preferência de Autran em trabalhar o íntimo das personagens. Em seu texto, Dourado se utiliza muito do discurso indireto e do fluxo de consciência da personagem, o que implica também em sua pontuação, que não indica ao leitor desavisado onde se limitam os pensamentos ou falas da personagem, que em certos momentos misturam-se ao narrador, já que a consciência pode emergir de forma abrupta ou desorganizada.

Olhe, moço, até hoje não paguei a promessa. Será que tem alguma coisa a gente atrasar um pouco? José Feliciano viu o terreno bom de plantação, o homem era crente; armando uma boa história, podia contar com ele. Não, a gente pagando chega, disse, Deus não tem tempo, o tempo a gente é que sabe quando. (DOURADO, 1995, p. 54).

Ainda discutindo um pouco da escrita de Dourado, observemos a próxima citação, retirada das palavras do próprio Autran em entrevista cedida a Senra (1983): "Você sabe, João, e melhor do que eu, que o problema não está em escrever depressa e sim em achar a palavra. O problema é a luta com a palavra" (SENRA, 1983, p. 6).

Percebemos o quanto Autran se preocupava em encontrar as palavras certas para encaixar em sua obra. Desde a escolha do título do livro até mesmo os nomes das personagens, tudo era carregado de significado. Tomemos como exemplo o nome da protagonista do livro Ópera dos mortos: Rosalina. Relacionado diretamente ao feitio das rosas produzidas pela moça.

Podemos expor as palavras do próprio Dourado, não só sobre esta personagem específica, mas sobre sua paixão pelas simbologias:

As coisas são o que são e significam. Tudo é símbolo e todo símbolo é mensagem. A personagem principal de meu romance Ópera dos mortos, que simbolicamente fabricava flores de papel, só podia se chamar Rosalina, de rosa. (DOURADO, 2003, p. 27-28).

Na obra de Autran nada é posto de forma aleatória ou solta, desde seu primeiro livro publicado o escritor consegue entrelaçar suas histórias em uma espécie de teia e, caminha por esta interligando principalmente suas personagens. Segundo a autora Senra 
(1983, p. 104): "suas personagens, embora solitárias, não existem sozinhas, ligam-se umas às outras, sem perceberem, subterraneamente."

\begin{abstract}
Autran Dourado, em sua forma peculiar de construir narrativas, apresenta ao leitor, mais do que simples histórias, enredos plenos de significados. Em seus romances e contos, tudo tem razão de ser, desde o nome dos personagens até o espaço onde se situam. Objetos e ambientes são apresentados como peças de enigmas ao leitor, à medida que ele penetra no texto. Apesar do alto grau de complexidade de seus romances, sua linguagem é leve e os discursos e os diálogos destacam o caráter oral, o jeito de falar do brasileiro e, em especial, do povo de Minas Gerais (OLIVEIRA, 2011, p. 53).
\end{abstract}

Mesmo que a preferência de Dourado seja pelo interior do homem, este só é possível de se moldar, de se construir, através da interferência do meio em que vive. Portanto, embora ele dedique sua escrita a explorar o íntimo das personagens, e talvez justamente por isto, ele não se afasta da história, já que este aspecto intrínseco ao ser humano, constrói-se também no ser ficcional, aproximando as relações entre poética e história. Pondo a literatura, ou a arte no geral, como algo concebido a partir da apreciação da realidade.

O interessante em Autran é que o autor não planeja simplesmente sua obra, a construção, mas também aquilo que espera que o leitor encontre. Em seu livro Uma poética de romance: matéria de carpintaria (1973) Autran questiona a falta de compromisso dos autores em aprimorar e analisar o que se produz. A produção germinaria no escritor, mas é o mundo exterior que explora, que critica e tende a tecer considerações sobre prováveis leituras. “[...] se há uma história ou fábula subliminar ou subterrânea em meus livros, há neles também um arspoetica, às vezes oculta e disfarçada, às vezes por demais aparente, as minhas "dicas" (DOURADO, 2000, p. 81)

Dourado já nos deixa entrever suas entrelinhas, principalmente ao "seu" leitor, não aquele que lê Autran pela primeira vez, mas aquele que só se satisfaz nas releituras.

Um exemplo deste diálogo com o leitor que já o conhece é a reutilização do quartafeirismo em suas personagens. A retomada de personagens compostos de uma loucura mansa que só são capazes de ferir a si mesmos. "No quarto, dona Genu se encolhia com medo que ouvissem da rua, quê que iam pensar dele? Maluqueira, telha-de-menos, quartafeira" (DOURADO, 1995, p. 21); "Meio quarta-feira, foi o que ele virou" (DOURADO, 1995, p. 61). "Eu devo estar é mesmo de ideia virada, quarta-feira às vezes me chamam, você não se lembra daquela vez na Itapecerica?” (DOURADO, 1985, p. 52) “O estúdio 
cavaleiro se chamava Lucas Procópio Honório Cota. Não era muito certo da cabeça, quarta-feira manso" (DOURADO, 1985, p. 18).

Mesmo que o autor possibilite uma interpretação guiada por sua obra, Autran apropria-se das técnicas do estilo barroco em sua construção. Essa propriedade não se aplica somente às descrições de edificações, tais como o sobrado em Ópera dos mortos (1995), - muito intrigante quanto a relação simbólica entre o prédio e seus proprietários que transmitem ao local suas personalidades, mas também quanto a ideia de que a leitura pode ter múltiplas faces, portanto, inúmeras maneiras de ser vista, ou seja, é possível mais de uma interpretação.

[...] um estilo prismático, em que as impressões são comunicadas através de diversas facetas [...] uma ação é privada de sua análise imediata, aparecendo quebrada em uma multidão de impressões desconexas ou não relacionadas; tal como um raio de luz dividido por um prisma, há entre o autor e o receptor a descrição de um olho, um ouvido ou outro receptáculo sensorial do herói que influi na impressão (COUTINHO, 2004, p. 230).

Tomemos agora as palavras do próprio Autran sobre o fazer poético e a relação com o barroco e os vários caminhos para se chegar ao entendimento de sua obra. "A arte como construção [...]. Jogo e construção, o aspecto lúdico da montagem, a múltipla leitura que o barroco propõe, tudo isso a cada vez me fascina mais e mais" (DOURADO, 2000, p. 57)

Ao criar uma obra que recorre a ela mesma é compreensível que o autor queira, juntamente a esse "aspecto lúdico da montagem", que sua obra se distancie da realidade. Estudando mais a fundo a estilística autraniana nos deparamos com sua vontade de se descompromissar na produção de romances realistas, e de se aprimorar muito mais na arte da construção poética, no fazer literário em prol da própria literatura.

Vejamos o que Autran nos fala sobre a relação entre realidade e ficção, qual a importância da primeira em apoio a construção da segunda.

Ora, os romancistas e novelistas, na sua modéstia e simpleza aparentes, sabem que usam do real com inteira liberdade. Sabem que o personagem tem a ver é com a realidade dentro do livro, a realidade do romance, com a sua arquitetura [...] e não com a realidade do meio em que vivem os homens, de que eles romancistas e novelistas se utilizam como barro. O criador amassa e emprega a realidade para criar uma outra realidade, uma realidade que obedece à complicada geometria 
literária, ao seu sistema de forças, que nada tem a ver com as ciências físicas, naturais ou sociais (DOURADO, 2000, p. 95).

Aqui o escritor nos reforça a ideia de que a personagem é um ser que sobrevive dentro de seu contexto, e que, apesar da "inspiração" vinda da realidade, após o nascimento da obra nada mais a associa ao real do homem. Tal pensamento se contrapõe ao que diz respeito a literatura como construtora ou modificadora de uma realidade. Além de servir como "barro" para a literatura, a realidade pode ser transformada ao se tornar visível através da arte. Vejamos o que o filósofo húngaro Georg Lukács (2010) afirma sobre a literatura realista:

[...] A literatura pode representar os contrastes, as lutas e os conflitos da vida social tal como eles se manifestam no espírito, na vida do homem real. Portanto, a literatura oferece um campo vasto e significativo para descobrir e investigar a realidade. Na medida em que for verdadeiramente profunda e realista, ela pode fornecer, mesmo o mais profundo conhecedor das relações sociais, experiências vividas e noções inteiramente novas, inesperadas e importantíssimas (LUKÁCS, 2010, p. 80).

Lukács (2010) nos confirma sobre a relação social que a literatura tem com a realidade, no entanto, é justamente neste ponto que Autran Dourado tenta um afastamento, principalmente no que se refere às questões históricas. O núcleo de suas tramas, por exemplo, se concentra na cidade fictícia de Duas Pontes, essa é uma entre outras técnicas do autor para afastar sua criação de um ponto histórico geográfico real. Outro aspecto é não mencionar datas específicas e só é possível situarmos o momento da narrativa graças às ações e os percursos das personagens, bem como os títulos mencionados que nos remetem à, por exemplo, como na citação abaixo, época da monarquia:

Firmino Albuquerque do Mares Guia atingiu uma das maiores posições a que um político daqueles tempos podia aspirar. Além o título de nobreza, Barão das Águas Claras, de destacava como membro do Conselho de Estado de Sua Majestade o Imperador (DOURADO, 1985, p. 54).

Autran demonstra não ter o propósito de situar suas estórias em um tempo cronológico preciso, no entanto, quando cruzamos a narrativa de Autran com fontes históricas constatamos o contrário. 
Ainda sobre a feitura sua obra Dourado nos apresenta:

O romancista, como todo artista, não cria para exprimir coisa alguma; ao contrário, exprime-se para criar [...]. Se o importante fosse o ato de exprimir e não o de criar, se o importante fosse o que o romancista tem a dizer e não o seu impulso criador e o seu dom de dar vida às coisas e aos seres, ele poderia perfeitamente escolher qualquer outro meio de comunicação moderno, mais direto e atuante, de massa mesmo [...] (DOURADO, 2000, p. 111).

Para Autran as técnicas envolvidas na construção de um romance são elementos que contribuem para a elaboração da estrutura de um mundo novo, o literário, que os princípios que regem a realidade são diferentes daqueles que colaboram para o acontecimento da vida da personagem, por exemplo.

Entretanto, voltamos a ideia de que a arte pode ser representativa da realidade. Vejamos o que nos diz o historiador Chartier (1999) sobre a representação:

[...] o conceito de representação é a de variabilidade e da pluralidade de compreensões (ou incompreensões) do mundo social e natural. [...] As lutas de representações têm tanta importância como as lutas econômicas para compreender os mecanismos pelos quais um grupo impõe [...] a sua concepção de mundo social, os valores que são os seus, e o seu domínio (CHARTIER, 1999, p. 21).

Historiadores já reconhecem no texto literário cenários que são capazes de captar materiais históricos mesmo que através do olhar particular do escritor. Portanto, tentaremos aqui alavancar a discussão sobre a possibilidade de representação histórica escrita por Autran, mesmo quando este declara abrir mão de tal função em sua obra. Será possível alcançar o total afastamento entre Literatura e História ou as estratégias autranianas não foram capazes de tal feito?

Dentro de todo o universo ficcional, por onde circulam os familiares do clã Honório Cota, analisaremos as simbologias e estratégias deixadas por Autran na tentativa de afastar-se da história. 


\section{O clã Honório Cota sob o crivo da análise da crítica literária}

Abriremos agora um espaço para um breve resumo com análise da primeira parte do livro Lucas Procópio, avô e fundador no Clã Honório Cota na trilogia (Ópera dos mortos, Um cavaleiro de antigamente e Lucas Procópio) de Dourado.

O Clã iniciado por Lucas Procópio deveria ter como precursor um Lucas sonhador, que almejava a volta da Era do Ouro de Minas Gerais e todo o seu glamour reluzente. Desprovido de anseios econômicos, encontrava na arte literária o prazer do belo, e sentia-se na obrigação de repassar seus conhecimentos poéticos para instruir os homens comuns, a fim de torná-los mais sábios e elevados, para que assim fosse possível tornar real seu sonho utópico e cavalheiresco sobre Minas.

Destinado a tomar posse da fazenda de seu pai Lucas sai pelos caminhos de Minas seguido por dois empregados. O preto Jerônimo que, mesmo alforriado, seguia-o por admirar sua sabedoria e devoção às poesias, comparando-as às histórias e lendas de seu povo. Pulsava em Lucas a mesma adoração fervorosa de Jerônimo, apesar de diferentes causas, a finalidade resumia-se ao credo de melhorias.

Além de Jerônimo seguia na caminhada um capataz branco e pobre que permanecia ali simplesmente pela ambição, Pedro Chaves, sempre em busca de riquezas e bens materiais, achava um desperdício a fixação do patrão na poesia. Deixado a porta de uma igreja ainda criança, Pedro sempre esteve ao lado da miséria. Era difícil para aquele faminto de pão pensar sobre a fome da alma.

Lucas Procópio era muitas vezes considerado como um louco ao propagar suas ideias e realizar, em público, as leituras de poemas. Tomava para si o título de Dom Quixote por, assim como o personagem de Cervantes, estar emocionalmente envolvido com a literatura e, a partir dela, buscar melhorias não só na paisagem mineira, bem como na alma humana.

Já na primeira parada os viajantes são recebidos por chacotas e Autran nos dá indicações sobre sua localização. Um morador especula que os três talvez estivessem indo à cidade de Jacuí, fazendo referência a decadência do lugar e sua outrora riqueza, assim como o cavalheiro que ali avistaram. Aqui voltamos ao nosso questionamento: como Autran conseguiria desprender a história de sua ficção se nos traz no enredo, através da inferência, mesmo que de um mero morador sem nome, de uma cidade de construção e declínio tão similar ao seu protagonista e ainda assim explicá-la ao leitor? 
[...] Jacuí era uma cidade antiga de velha, tinha sido das primeiras cabeças de comarca nos tempos da outroramente Minas colonial: quando o ouro brotava do chão, extraído facilmente [...]. Jacuí era agora uma lástima agonizante, voltara a ser termo e distrito: até as galas da cidade lhe tiraram, comarca deixou de ser. [...] pra lá devia ir o cavalheiro, [...] fantasma de um cemitério a que devia retornar (DOURADO, 1985, p. 16, grifo nosso).

Jacuí e Lucas constroem-se e crescem através da mineração, mas se encontram em ruínas pela escassez do ouro. Dourado se preocupa em ressaltar ao leitor que tudo não passava de especulações, mas é notória a semelhança entre o cavalheiro e a cidade.

Na citação acima temos também indícios do tempo em que se encontra a narrativa, já que ao classificar Minas colonial como “outroramente" já nos permite a exclusão de um período histórico brasileiro, e nos limita a sua posterioridade.

Em outras passagens do texto Autran deixa Lucas Procópio em Itapecerica, município mineiro fundado em 1789, dando-nos mais indícios da localização da narrativa no que se refere o tempo. Nesta cidade acompanhamos as lutas dos moradores em prol da República. “[...] Lembrai-vos da Revolução Francesa, quando o povo unido e armado derrubou a opressão e a monarquia. Hoje somos nós, amanhã será toda a Província e o Brasil. Viva a República!" (DOURADO, 1985, p. 23).

Enquanto a população fervia em gritos de renovação da forma de governar, Lucas aparece alheio a tais questões, envolvido nos "mais líricos e heróicos versos" (DOURADO, 1985, p. 23) como a própria personificação dos desejos de Autran, de afastar-se da história, mesmo quando ela o cercava.

Mesmo que Lucas Procópio se distancie, ou tente se distanciar, da história, o protagonista está em vários momentos nos dando indícios reais da construção ou declínio de Minas. Em algumas passagens acompanhamos a simbologia do fardamento vestido por Lucas, mas de propriedade de seu avô. As vestes serviam para aproximá-lo das ilusões e do período almejado.

Vejamos agora dois momentos da personagem a respeito da roupa:

Um antigo velhinho mestre regente da casa da ópera disse ele usa essa farda porque tem vocação inata para o palco, e ele só declamava poemas patrióticos. Entre eles, preferia a epopeia Vila Rica, de Cláudio Manuel da Costa, que assentava muito bem com a farda de gala (DOURADO, 1985, p. 51). 
Enquanto a personagem encontra-se mascarada pela farda de seu avô suas predileções destinam-se a literatura, ao imaginário, principalmente aquele direcionado ao grandioso, relacionando-o aos seus desejos pela magnificência de Minas Gerais.

Tirando a mania do fardamento, todas as suas ideias eram absolutamente normais. Dele se ouviam os conselhos mais judiciosos e sentados, tinha tino e sabença. Nas ágoras da cidade predicava sobre assuntos elevados e exaltava as virtudes femininas. Se se queria saber a história antiga de Minas, ele exaltava as vidas gloriosas de Felipe dos santos e Tiradentes (DOURADO, 1985, p. 51).

Observemos que enquanto trajava a vestimenta de gala, Lucas se associava aos literatos, ou mais precisamente às suas criações. Já destituído de tal recurso aproximavase de personagens reais mineiros e tinha uma maior afinidade com os homens da região.

Em outro momento podemos acompanhar mais uma vez a associação dos trajes à certa loucura de Lucas Procópio. Observemos:

Na primeira oportunidade, perguntou a Ismênia se Lucas Procópio continuava com seus trajes do século XVIII. Não, disse ela, absolutamente, ele recuperou o juízo. O senhor conhecerá um dos homens mais finos, cultos e elegantes do Império (DOURADO, 1985, p. 59).

Se o traje pertencia ao avô e datava do século XVIII, é possível calcularmos que a narrativa de Autran encontra-se, provavelmente no início do século XIX. E, mesmo que o autor aproprie-se de estratégias para afastar o leitor de uma ficção histórica, até mesmo os títulos políticos mencionados são vestígios de determinada época.

Firmino Albuquerque dos Mares Guia atingiu uma das maiores posições a que um político daqueles tempos podia aspirar. Além do título de nobreza, Barão das Águas Claras, se destacava como membro do Conselho de Estado de Sua Majestade o Imperador (DOURADO, 1985, p. 54).

Talvez pelo porte, ou pelo título de baronesa, a esposa do barão despertava sentimentos em Lucas Procópio, que há muito tempo não se desvencilhava das aventuras cavalheirescas. Seria Ismênia a Dulcinéia do cavalheiro Procópio?

Para Ismênia o romance era uma forma de fuga do casamento infeliz com um homem mais velho que não lhe proporcionava as alegrias desejadas, para Lucas era um 
fio que o puxava a realidade e o fazia desgrudar de seus mais ambiciosos sonhos: educar as pessoas pela poesia e a partir disso reerguer as Minas de Ouro.

Foi pensando em seus propósitos que, durante uma festa na casa do Barão, já conhecedor de seu romance com Ismênia, desistiu do amor em razão de mais uma falha tentativa de atingir tais sonhos.

Tinha de ser aquela noite, afinal havia na casa gente importante, ele de hóspede de um barão e ainda por cima membro do Conselho de Estado: poderia ser levado à presença de Sua Majestade o Imperador Dom Pedro II, para lhe expor um plano grandioso não só para Minas Gerais, como para o Brasil [...] Nunca teve um auditório tão seleto para a sua pregação cívica, para a redenção de Minas pela poesia. (DOURADO, 1985, p. 61).

Mais uma vez Lucas deixa de lado os desejos mais próximos da realidade, como o romance com Ismênia, para voltar ao universo da poesia, a áurea do grandioso, do literato, nunca o deixava totalmente e era por ele muito mais aclamada e aplaudida do que a veracidade, já que o momento político caminhava para o final da Monarquia e fundação da República, bem como citado anteriormente. No entanto, o que Lucas queria era voltar no tempo, coisa que só lhe era possível graças à ficção, graças a literatura.

Voltemos agora às vidas daqueles dois que lhe seguiam, o escravo alforriado Jerônimo e o capataz Pedro Chaves. Depois da frustração da noite na casa do barão Lucas seguiu seu caminho na direção da Fazenda do Capão Florido, Jerônimo em busca de quilombos onde pudesse encontrar sua paz e seu povo e Pedro Chaves em sua caçada por riquezas materiais. A união dos três se dá pelo acúmulo de memórias, nenhum consegue se desgruda do passador, mesmo que queira, como é o caso de Pedro Chaves. Enquanto Lucas e Jerônimo tentam voltar no tempo para épocas melhores, Pedro esquecer que veio de baixo, do ódio que sente por isso e de que os que dali vieram poucos tem a chance de subir na vida.

Sobre este relacionamento dos três, Santos (2008, p. 122) nos mostra que "nessa longa caminhada, o convívio dos três personagens com histórias de vida tão distintas dinamiza a narrativa que se constrói num plurivocalismo especial”, que para Bakhtin (SANTOS, 2003, p. 196) significa "colocar o homem em diferentes situações que o revelem e o provoquem, juntar personagens e levá-las a chocar-se ente si”. O que funciona muito bem em Autran ao reunir personagens tão distintas, e ainda assim capazes de se aproximarem. 
Ao nos apresentar Jerônimo o escritor nos mostra o que vai além da história de Minas. Conhecemos o outro lado da escravidão, aquele que geralmente não é contato, já que as vozes dos dominados não ecoam com tanta força, e não ganham tantos ouvidos como as dos dominadores.

Finalizando a primeira parte do livro de Autran Dourado, dividido somente em dois blocos, o leitor se depara com a brusca mudança de destinos ocasionada por Pedro Chaves, que, em um momento oportuno desfere sobre Lucas um tiro capaz de tirar-lhe a vida. Mesmo que Jerônimo tente impedir, a sede de subir na vida cega Pedro que não titubeia nem um segundo, até porque esta não é a primeira morte que carrega em suas costas, já que Pedro chega até a família de Lucas justamente fugindo da justiça por ter matado alguém anteriormente,

A partir de tal feito percebemos que toda a família construída dali em diante não pertence de fato aos Honório Cota, mas ao usurpador da vida de Lucas, Pedro Chaves.

Na segunda parte conhecemos a família de Isaltina, aquela que um dia se tornaria esposa de Lucas Procópio (Pedro Chaves) em troca de um belo dote cedido ao pai da moça que se encontrava na falência pelo vício em jogo.

\section{CONSIDERAÇÕES FINAIS}

De acordo com a análise anterior compreendemos que o autor, mesmo utilizandose de estratégias para se afastar da história não alcança tal feito. Uma vez que suas personagens são apresentadas ao leitor dentro de determinado tempo sócio histórico. Sendo possível apontarmos os eventos da narrativa em determinado contexto histórico, seja através de suas atitudes, menções, cargos ou expressões.

Compreendemos que uma obra literária abarca muito do contexto histórico e social de uma época, e que, mesmo se tratando de fruto da imaginação do autor, os textos literários só surgem graças a sua observação sobre o mundo externo. Sendo assim, as personagens recebem características próprias de sua época e só desempenham funções e/ou ações próprias do contexto em que são inseridas. Servem, portanto, como fonte para estudos acerca das questões históricas.

\section{REFERÊNCIAS}


CHARTIER, Roger. Debate: literatura e história. In: Revista Topoi, Rio de Janeiro, n. 1, p. 197-216, 1999.

COSTA, Flávio Moreira da. Questões de vida e de morte. São Paulo: Opinião, 1974. Disponível em:

<http://memoria.bn.br/DocReader/Hotpage/HotpageBN.aspx?bib=123307\&pagfis=233 0\&pesq=\&url=http://memoria.bn.br/docreader\# > Acesso em: 01 dez. 2017.

COUTINHO, Afrânio. A Literatura no Brasil. 7. ed. São Paulo: Global, 2004.

DOURADO, Autran. Lucas Procópio. Rio de Janeiro: Record, 1985.

Ópera dos mortos. 12. ed. Rio de Janeiro: Francisco Alves, 1995.

Uma poética de romance: matéria de carpintaria. Rio de Janeiro: Rocco, 2000.

Breve manual de estilo e romance. Belo Horizonte: Editora da UFMG, 2003.

LUKÁCS, György. Marxismo e teoria da literatura / seleção, apresentação e tradução de Carlos Nelson Coutinho. 3. ed. São Paulo: Expressão popular, 2010.

OLIVEIRA, Marcio da Silva. As influências do trágico nos romances contemporâneos Ópera dos mortos e Os sinos da agonia, de Autran Dourado. 2011, 143 f. Dissertação (Mestrado em Letras) - Universidade Estadual de Maringá, Maringá. Disponível em: 〈http://www.ple.uem.br/defesas/pdf/msoliveira.pdf > Acesso em: 17 de jun. de 2017.

SANTOS, Leonor da Costa. Autran Dourado em romance puxa romance ou a ficção recorrente. 2008. 214f. Tese (Doutorado em Letras Vernáculas- Literatura Brasileira) Faculdade de Letras da Universidade do Rio de Janeiro, Rio de Janeiro. Disponível em: $<$ http://www.letras.ufrj.br/posverna/doutorado/SantosLC.pdf> Acesso em: 23 mai. 2017.

SENRA, Angela Maria de Freitas. Literatura Comentada: Autran Dourado. São Paulo: Abril Educação, 1983.

Recebido em: 20 abr. 2018

Aceito em: 22 mai. 2018 